\title{
Política e saúde em dois coletivos femininos nas redes sociais: uma análise durante a pandemia de Covid-19
}

\author{
Gisleine Durigan' \\ Claudio Bertolli Filho²
}

\section{Resumo}

Este artigo tem o objetivo de analisar como as usuárias das redes sociais on-line, organizadas em dois diferentes coletivos, reagiram diante do contexto pandêmico, identificando suas formas de interação e investigando como as relações nas plataformas digitais, em especial no Facebook, podem influenciar nos comportamentos individuais e coletivos. A partir dos referenciais metodológicos da análise de conteúdo e a hermenêutica de profundidade foram analisados dois grupos femininos com expressiva atuação no cenário político atual: "Mulheres Unidas Contra Bolsonaro" e "Mulheres de Direita Unidas Pelo Brasil". Os resultados obtidos evidenciam a polarização nos posicionamentos referentes às medidas de enfrentamento da pandemia e a significativa presença da desinformação entre os conteúdos compartilhados, ou seja, o crivo do posicionamento dos grupos deu-se mais pelo viés político-partidário do que por fontes seguras científica-institucionais.

Palavras-chave: Redes sociais. Covid-19. Análise de conteúdo. Hermenêutica de profundidade. Coletivos femininos.

\footnotetext{
' Doutoranda em Comunicação pela Universidade Estadual Paulista (Unesp), Mestre em Mídia e Tecnologia também pela FAAC/ Unesp e graduada em Comunicação Social com habilitação em Jornalismo pela mesma instituição.

2 Livre-docente aposentado da Universidade Estadual Paulista (Unesp) atuante junto ao Programa de Pós-graduação em Comunicação da mesma instituição.
} 


\title{
Politics and health in two female collectives on social networks: an analysis during the Covid-19 pandemic
}

\begin{abstract}
This article aims to analyze how users of online social networks, organized in two different collectives, reacted to the pandemic context, identifying their forms of interaction and investigating how relationships on digital platforms, especially on Facebook, can influence individual and collective behaviors. From the methodological frameworks of content analysis and in depth hermeneutics, two female groups with an expressive performance in the current political scenario were analyzed: "Women United Against Bolsonaro" and "Women of the Right United for Brazil". The results obtained show the polarization in the positions regarding the pandemic coping measures and the significant presence of misinformation among the shared contents, that is, the sieve of the groups' positioning was more due to the political-partisan bias than to reliable scientificinstitutional sources.
\end{abstract}

Keywords: Social networks. Covid-19. Content analysis. Depth hermeneutics. Female collectives.

\section{Introdução}

O surgimento da internet e das tecnologias midiáticas provocaram transformações expressivas em todas as esferas sociais, alterando, significativamente, os paradigmas da Comunicação. Os indivíduos que antes eram, fundamentalmente, receptores da informação, passaram a produzir e compartilhar seus conteúdos em uma rede global. Mesmo antes do advento das redes sociais on-line, a internet possibilitou a formação de comunidades, em uma plataforma virtual, ampliando as oportunidades de discussão coletiva (POLAT, 2005).

Posteriormente, a emergência das redes sociais on-line e a popularização dos dispositivos móveis causaram transformações ainda mais profundas nas relações midiáticas e sociais contemporâneas. Mediada pela tecnologia, a formação de grupos com interesses comuns se fortaleceu, assim como a interação entre os participantes desses coletivos e suas articulações em prol de seus objetivos. 
Como aponta Angeluci (2014), o ambiente on-line em redes favorece a lógica participativa, com a interatividade e o compartilhamento entre os indivíduos, em diversos níveis. Dessa forma, facilita-se o engajamento, tendo as figuras de produtor e receptor de conteúdos, indivíduo e coletivo fundindo-se em uma complementariedade, nem sempre pautada pela coerência. O digital, assim, atua como locus da cultura participativa, na qual as práticas colaborativas são potencializadas em um espaço de representação do coletivo.

Nesse meio de intensas trocas e conexões, o grande volume de conteúdos informacionais produzidos, e rapidamente disseminados no ambiente on-line, também favorece a prática do compartilhamento imediato, levando, muitas vezes à desinformação. O consumo e a divulgação das notícias por meio das redes sociais, frequentemente, de modo instantâneo, sem um apuro adequado, têm gerado sérias consequências em diversas esferas da sociedade.

Como aponta Delmazo e Valente (2018), apesar das notícias falsas serem um fenômeno antigo, a disseminação pelas redes sociais on-line e a cultura de partilha fez com que a desinformação atingisse um novo patamar. Dessa forma, o consumo de notícias falsas pelas redes sociais ganhou a capacidade de influenciar o comportamento de diferentes públicos, acentuando, inclusive a polarização política do país.

Nesse contexto, marcado pela comunicação em redes que trouxe transformações significativas para toda a sociedade, surge a primeira pandemia do século XXI. No dia 11 de março de 2020, a Organização Mundial da Saúde (OMS) declarou a Covid-19, doença causada pelo coronavírus da Síndrome Respiratória Aguda Grave 2 (SARS-CoV-2) como uma pandemia. O vírus, que foi identificado pela primeira vez em um grupo de pacientes com pneumonia atípica em Wuhan, China, no dia $1^{\circ}$ de dezembro de 2019, logo cruzou fronteiras e se espalhou pelo mundo.

Depois de 11 meses e meio do primeiro caso identificado, mais de 53 milhões de casos foram confirmados com 1.301 .021 óbitos $^{3}$ (em 14 de novembro de 2020, às 05h40) em 188 países. No Brasil, o primeiro caso confirmado de Covid-19 foi no dia 26 de fevereiro de 2020, com o primeiro óbito registrado 20 dias depois, em 17 de março. Até o

\footnotetext{
${ }^{3}$ De acordo com dados da Organização Mundial da Saúde.
} 
momento (em 14 de novembro de 2020, às 05h50) foram confirmados 5.811 .699 casos e 164.855 óbitos $^{4}$ em todo o país.

Neste cenário de crise sanitária mundial, diante de uma nova doença sobre a qual pouco se sabia antes do vírus já se espalhar pelo mundo, a busca por informações foi intensificada, assim como a produção e compartilhamento de notícias que não correspondem com a veracidade das descobertas científicas e constatações epidemiológicas sobre a doença. Com isso, mesmo com os empenhos das mídias tradicionais e dos órgãos públicos, a desinformação relacionada ao novo coronavírus no ambiente on-line tem levado ao estado de caos, como aponta Souza Júnior, Raasch, Soares e Ribeiro (2020).

Além disso, as plataformas de redes sociais, inicialmente identificadas como propulsoras de propósitos democráticos e plurais, nos últimos anos, acentuaram polarizações, a partir do funcionamento de algoritmos que expõe seus usuários a determinados conteúdos e não a outros. Assim, no lugar da pluralidade de informações e conteúdos, o que se observa é o fortalecimento de consensos polarizados não só acerca de temas políticos, mas sobretudo comportamentais (MACHADO; MISKOLCI, 2019).

Diante de todo o exposto, o objetivo do presente artigo é analisar como os usuários das redes sociais on-line, organizados em diferentes grupos, reagiram diante do contexto pandêmico, identificando quais informações tiveram maior circulação, quais comportamentos foram estimulados e quais temas foram mais recorrentes, relacionando os dados encontrados com a conjuntura social e política nacional. Assim, a pesquisa tem o propósito de investigar como as relações nas plataformas digitais, em especial no Facebook, podem influenciar os comportamentos individuais e coletivos, considerando o período analisado.

\section{Metodologia}

Para realizar a pesquisa e alcançar os objetivos propostos, os referenciais metodológicos empregados são a análise de conteúdo (BARDIN, 2016) e a hermenêutica de profundidade (THOMPSON, 2011). Como preconiza Bardin (2016), os dados coletados passarão por quatro procedimentos principais: a pré-análise, codificação, categorização e, por fim, a inferência/análise. Aliada a essa metodologia, a utilização da hermenêutica de

\footnotetext{
${ }^{4}$ De acordo com dados do Ministério da Saúde do Brasil.
} 
profundidade permitirá uma interpretação mais acurada acerca da construção simbólica do objeto de análise.

Segundo Bardin (2016, p.15), a análise de conteúdo atualmente é: "Um conjunto de instrumentos metodológicos cada vez mais sutis em constante aperfeiçoamento, que se aplicam a 'discursos' (conteúdos e continentes) extremamente diversificados". Com procedimentos sistemáticos que permitem a inferência dos elementos de significações das mensagens, a análise de conteúdo é um método empírico muito adaptável ao vasto campo de aplicação das comunicações.

Sob essa perspectiva, apesar dos procedimentos serem bem definidos, também são flexíveis, dependendo do objeto de pesquisa. No entanto, ao realizar o percurso metodológico, desde o primeiro contato com o material coletado, Bardin (2016) recomenda que sejam identificados os indicadores que vão orientar a interpretação, com a elaboração de um plano de análise preciso.

Como um referencial metodológico complementar, a hermenêutica de profundidade permite compreender a produção e circulação de mensagens; a construção de formas simbólicas e a recepção e apropriação dessas formas pelos indivíduos. Desse modo, a metodologia é indicada em pesquisas na área da Comunicação, uma vez que conduz a uma visão processual, com uma perspectiva crítica e mais próxima dos atuais contextos comunicacionais. Além disso, com esse referencial metodológico, que inclui formas de análise complementares entre si, é possível analisar a ideologia como uma vertente social presente no âmbito pesquisado.

Para Thompson (2011), o mundo sócio-histórico é um campo-sujeito arquitetado pelas pessoas por meio de formas simbólicas, as quais define como as diversas ações, falas, imagens e textos. Assim, na primeira fase, Análise Sócio-histórica, é preciso reconstituir as condições sociais de produção, circulação e recepção dessas formas simbólicas, analisando as situações no tempo e espaço e suas interações nas estruturas sociais e de poder. Na segunda fase, Análise Formal ou Discursiva, parte-se do pressuposto de que as formas simbólicas são construções complexas com uma estrutura articulada e, assim, deve-se analisar quais as relações entre as formas simbólicas e o contexto sócio-histórico. Por último, na Interpretação/Reinterpretação deve ser explorado todo o potencial crítico da pesquisa, superando as aparências evidentes e contribuindo para a construção de um saber de sentido emancipatório. 
No entanto, Thompson (2011, p. 365) ressalta: "Essas três fases devem ser vistas não tanto como estágios separados de um método sequencial, mas antes como dimensões analiticamente distintas de um processo interpretativo complexo". Assim, diferentes tipos de análise podem ser integrados de uma maneira sistemática, possibilitando a investigação da contextualização social e a constituição das formas simbólicas.

\section{Grupos femininos nas redes sociais}

A partir dos referenciais metodológicos escolhidos, dois grupos femininos, da rede social Facebook, foram selecionados para a realização da análise: "Mulheres Unidas Contra Bolsonaro" e "Mulheres de Direita Unidas Pelo Brasil". Os coletivos foram adotados devido a sua expressiva atuação no ativismo digital e, consequente repercussão nacional, dando origem a ações políticas como a disseminação do uso das hashtags \#EleNão e \#EleSim. A mobilização que nasceu nas redes sociais, durante a campanha eleitoral de 2018, fortaleceu-se e ganhou as ruas de todo o país, ganhando destaque na imprensa ${ }^{5}$ e no cenário político. Os coletivos femininos, que surgiram com o propósito inicial de se mobilizarem a respeito da candidatura de Jair Bolsonaro à Presidência da República, de forma apartidária, continuaram ativos após as eleições de 2018.

Posicionados, inicialmente, contra e a favor do candidato, os grupos prosseguiram com as interações entre as participantes, compartilhando notícias e conteúdos alinhados a ideais e objetivos pelos quais se mobilizaram durante a campanha. Atualmente, o grupo que se posicionou contrário à candidatura de Bolsonaro possui 2,3 milhões de membros e o outro, que se mobilizou de modo favorável, apresenta 372,9 mil mulheres.

Para se protegerem de ataques cibernéticos, que inclusive ocorreram intensamente antes das eleições de 2018, os grupos no Facebook são fechados, ou seja, os perfis interessados em fazer parte dos grupos precisam ser aprovados pelos moderadores para conseguirem participar. Apesar dessa característica, a opção pela análise desses grupos justifica-se pelo entendimento de que a atuação desses coletivos tem provocado consequências significativas na vida de toda a sociedade brasileira.

5 "Mulheres se unem nas redes contra Bolsonaro". Disponível em: $<$ https://politica.estadao.com.br/noticias/eleicoes,mulheres-se-unem-nas-redes-contrabolsonaro,70002500084 >. Acesso em 14 de novembro de 2020. 
Como aponta Pires e Motta (2020, p.145), o movimento \#EleNão, originalmente organizado por mulheres de todo o Brasil por meio de um grupo no Facebook, levou centenas de pessoas às ruas, exercendo grande influência no cenário político do Brasil: "O movimento foi decisivo para levar as eleições para o segundo turno e demonstrar o quanto a internet e, principalmente, as redes sociais têm um grande poder de mobilização".

As autoras Sousa e Rachit (2019) também consideram que mais do que uma ação coletiva, a campanha \#EleNão, nascida no Facebook, representa um movimento social contemporâneo que nasce no ambiente on-line, mas que contribui para a construção de comunidades com práticas transformadoras que se consolidam no espaço físico:

O movimento cresceu e se fortaleceu no ambiente online com a criação de comunidades instantâneas, mas se consolidou efetivamente no espaço físico urbano com ações coletivas de transformação social. A vocalização das reivindicações do grupo nas ruas foi importante para evidenciar a unidade do movimento. O número expressivo de manifestantes nos protestos do dia 29 de setembro de 2018 teve impacto e repercussão não só nas redes como também nos meios de comunicação tradicionais, a exemplo dos telejornais, que pautaram os atos ocorridos nas diversas cidades do Brasil e do mundo. (SOUSA; RACHIT, 2019, p. 84)

Em relação ao grupo feminino de posição oposta, que originou o movimento \#EleSim em prol da candidatura de Bolsonaro, apesar de não terem sido encontrados estudos científicos especificamente acerca do seu papel, o próprio fato do candidato sair vitorioso nas eleições presidenciais atesta a relevância do coletivo. Ademais, diante da inexistência de estudos específicos sobre este grupo feminino, que se contrapôs ao movimento \#EleNão, evidencia-se o ineditismo da presente pesquisa e sua contribuição não só no universo acadêmico, mas também para a melhor compreensão do cenário político e social da atualidade.

A escolha por dois grupos de gênero semelhante (mulheres), mas com posições politicas e culturais antagônicas, para analisar como interagem diante do contexto pandêmico, explica-se uma vez que um dos objetivos é também investigar se a polarização política se reflete na forma como os membros dos grupos recebem e incorporam as notícias referentes à Covid-19 e quais comportamentos são estimulados.

Como afirma Lima, Buss e Paes-Sousa (2020) a pandemia magnifica as tensões existentes na organização social do tempo em que acontece. Dessa forma, a Covid-19 
evidencia as características ou sintomas da atualidade como uma sociedade interconectada digitalmente, mas impregnada de desinformação; globalizada nas trocas econômicas, porém enfraquecida como projeto político global; carente de ideais políticos, mas avessa à política e projetos comuns. Mais do que uma crise sanitária, os autores afirmam que o novo coronavírus trouxe uma crise humanitária “(...) temos de considerar as epidemias e, sobretudo, pandemias como a que vivemos como um fenômeno multidimensional, a um só tempo, biológico, ambiental e social, com fortes implicações econômica e política" (LIMA; BUSS; PAES-SOUSA, 2020, p. 02).

Diante disso, os dois grupos femininos mostraram-se ser o objeto de análise mais indicado para o objetivo proposto, já que atuam no ambiente digital e são alinhados com diferentes propostas políticas e sociais.

\section{Coleta de dados}

Devido ao fato dos grupos femininos no Facebook serem fechados, seus nomes na análise serão preservados ${ }^{6}$, assim como as identidades de seus membros. Dessa forma, no artigo serão designados apenas como Grupo A (coletivo que se originou pela oposição à candidatura de Jair Bolsonaro) e Grupo B (coletivo formado para se posicionar favoravelmente ao candidato).

Para a análise, foram coletadas, de modo manual, as postagens dos dois grupos, no período entre 16 a 20 de abril de 2020. A opção pelo período analisado deve-se a um acontecimento político de forte impacto no contexto pandêmico: a demissão de Luiz Henrique Mandetta do cargo de Ministro da Saúde, em decorrência de desentendimentos com o Presidente da República Jair Bolsonaro. Como a demissão ocorreu no dia 16 de abril, o período de coleta foi definido para ser realizado durante cinco dias consecutivos, tendo início no dia do comunicado da demissão.

Por ter sido um acontecimento de grande repercussão nacional e internacional, evidenciando a crise política e sanitária que o país vivenciou, a demissão do mais alto cargo do ministério responsável pelas ações de proteção à saúde da população foi o momento selecionado para analisar as reações dos coletivos femininos à pandemia e

6 Devido ao caráter científico do artigo, os nomes dos grupos foram mencionados no tópico acima, apenas uma vez, para uma eventual averiguação do corpus analisado. Doravante, serão apenas designados como Grupo A e Grupo B. 
suas inter-relações com os comportamentos políticos e sociais no país. Para tanto, no período de cinco dias, foram coletadas as 30 postagens diárias da categoria mais "relevantes" (aspas nossa) de cada grupo no Facebook.

A categoria "relevantes" é gerada por meio dos algoritmos da plataforma digital, que seleciona as postagens com maior engajamento (mais curtidas e comentários). Para uma uniformidade científica, todas as coletas foram realizadas logo após às 23h59, a fim de garantir um intervalo temporal de $24 \mathrm{~h}$ e possibilitar a captura das 30 postagens mais relevantes depois desse período. Esse método foi escolhido diante da impossibilidade da captação manual ininterrupta das postagens dos dois grupos, que juntos possuem uma média diária de mais de 100 posts. Ao contrário de páginas e grupos abertos nos quais podem ser utilizados softwares para a captação dos posts, por se tratar de um grupo fechado, a única possibilidade é o print manual.

Dessa forma, foi estabelecida a coleta diária das 30 postagens mais relevantes de cada grupo, o que gerou 150 publicações de cada coletivo, totalizando um corpus de 300 postagens. Após a coleta dos dados, deu-se início às etapas de pré-análise, codificação e categorização, que fazem parte da metodologia de análise de conteúdo, como preconiza Bardin (2016).

Simultaneamente, como também se optou pelo uso da hermenêutica de profundidade, segundo Thompson (2011), foi realizado um levantamento do contexto social e político no qual a pandemia está inserida. Como a produção e circulação das mensagens não estão desvinculadas do seu entorno sócio-histórico, essa análise contextual possibilitará um aprofundamento crítico nas discussões dos resultados da pesquisa.

\section{Contexto político e pandêmico}

A pandemia do novo coronavírus, que chegou no Brasil no dia 26 de fevereiro, quando teve o primeiro caso confirmado, encontrou um cenário marcado por grandes instabilidades socioeconômicas, graves crises políticas deflagradas por disputas entre atores públicos dos três poderes - Executivo, Legislativo e Judiciário - e uma sociedade visivelmente polarizada, com a ascensão dos grupos conservadores. Nesse contexto, como aponta Ferraz (2020, p. 273): "Nunca a saúde e a política pareceram estar tão relacionadas como nesta pandemia da Covid-19" Assim, para aprimorar a análise das 
publicações dos grupos femininos, serão levantados os principais aspectos do contexto político até a data da última postagem em 20 de abril de 2020.

Um dos principais pontos a serem ressaltados diante dessa conjuntura é a posição do chefe de estado, Jair Bolsonaro, de minimizar a gravidade do novo coronavírus e se posicionar de forma contrária às recomendações da OMS. Desde o início da pandemia, tanto em seus discursos como em ações, o Presidente da República desestimula o isolamento social e as medidas de combate ao novo coronavírus. Uma notícia, inclusive, divulgada em 04 de maio de 20207, revela que, de acordo com uma pesquisa em desenvolvimento na Universidade de Cambridge em parceria com a Fundação Getúlio Vargas, os atos e discursos de Bolsonaro desfavoráveis ao isolamento social são responsáveis por pelo menos $10 \%$ dos casos de Covid-19 registrados até aquele período.

Segundo a pesquisa, dois acontecimentos em especial teriam provocado um movimento adicional de um milhão de pessoas nas ruas do país, diariamente, pelo período de 10 dias: a manifestação popular de 15 de março em Brasília contra o Congresso e o Supremo Tribunal Federal (STF), estimulada por Bolsonaro e da qual ele próprio participou, e o emblemático pronunciamento em rede nacional realizado no dia 24 de março de 2020 no qual afirma que a nação deveria voltar à normalidade e que devido ao seu histórico de atleta teria no máximo uma "gripezinha" (aspas nossa). Ao considerar o potencial de infecção de cada indivíduo portador do vírus, a estimativa é que esses dois atos foram responsáveis por pelo menos 500 novos casos por dia, o que em 10 dias são 10 mil infectados. Assim, de acordo com a pesquisa, isso representou 10\% do número de brasileiros oficialmente registrados como portadores da Covid-19 até um dia antes da data da publicação da notícia do estudo, ou seja, até 03 de maio de 2020.

Após esses dois eventos, o fato polêmico que acirrou ainda mais a polarização em torno da questão pandêmica foi a demissão do então Ministro da Saúde Luiz Henrique Mandetta, no dia 16 de abril de 2020, devido à discordância de Bolsonaro em relação às medidas de contenção do novo coronavírus defendidas por Mandetta que, por sua vez, também são as recomendadas pela OMS. Além do isolamento social, ambos divergiam

\footnotetext{
7 Disponível em: < https://ultimosegundo.ig.com.br/brasil/2020-05-04/covid-19-estudo-ligacomportamento-de-bolsonaro-a-10-das-mortes-no-brasil.html $>$. Acesso em: 14 de novembro de 2020.
} 
também sobre o tratamento com o uso da cloroquina, amplamente defendida por Bolsonaro, mas sem eficácia comprovada cientificamente.

Para Caponi (2020) um dos pontos essenciais para entender o descaso do presidente e de seus seguidores em relação à pandemia é a questão do negacionismo científico e a desconsideração de argumentos racionais em diversos âmbitos.

\begin{abstract}
Esse negacionismo que foi adotado pelo atual governo já na campanha eleitoral, com seu desprezo pelas universidades, pela pesquisa científica, pelos direitos das populações vulneráveis, pelas comunidades indígenas, LGBT, populações de rua, mulheres em situação de violência etc., agrava-se em tempos de epidemia, quando existe maior necessidade de um Estado presente que garanta o exercício dos direitos. Particularmente, no que se refere à pandemia, esse negacionismo se traduz na aceitação de intervenções sem validação científica, como a divulgação e exaltação de uma terapêutica de eficácia não comprovada e com efeitos colaterais extremamente sérios como a cloroquina, ou a defesa de um estratégia de intervenção que contraria a posição da Organização Mundial de Saúde (OMS),denominada por Bolsonaro como "isolamento vertical". (CAPONI, 2020, p. 210-211)
\end{abstract}

Aliada ao processo de negacionismo científico, a autora também expõe um outro ponto crucial no contexto pandêmico não só brasileiro, mas também de alguns outros países neoliberais como os Estados Unidos, por exemplo: a falaz oposição entre defender a vida ou defender a economia, como se fossem polos antagônicos. No caso brasileiro, essa aparente oposição foi um dos elementos centrais na discordância entre o presidente Bolsonaro que defendia a flexibilização do isolamento em prol da economia e os governadores estaduais que preferiam aderir a medidas mais restritivas de distanciamento social.

\title{
Análise e discussões dos resultados
}

A partir das considerações do contexto político e pandêmico e do material coletado, tiveram início os procedimentos de pré-análise, com a organização e exploração inicial dos dados. Em seguida, foi realizada a codificação, possibilitando que os dados brutos fossem suscetíveis de uma análise quantitativa e qualitativa. Nesta fase, a unidade de registro selecionada foi o tema, apontada por Bardin (2016) como característica da análise de conteúdo, e como regra de enumeração optou-se pela presença (ou ausência) e pela frequência. 
Com os critérios de codificação definidos, o próximo passo foi a categorização, estabelecendo as áreas temáticas. Para isso, a fase anterior de pré-análise foi essencial, pois foi observado um panorama dos assuntos e temas tratados. Dessa forma, para abarcar os assuntos das postagens dos dois grupos, os temas selecionados foram: (1) apoio ao Presidente da República Jair Bolsonaro; (2) crítica ao Presidente da República Jair Bolsonaro; (3) apoio à demissão do Ministro da Saúde Luiz Henrique Mandetta; (4) crítica à demissão do Ministro da Saúde Luiz Henrique Mandetta; (5) apoio às medidas sanitárias contra a propagação do novo coronavírus; (6) crítica às medidas sanitárias contra a propagação do novo coronavírus e negacionismo científico; (7) solidariedade às vítimas da Covid-19; (8) defesa dos direitos das mulheres; (09) ataque a adversários de Jair Bolsonaro; (10) outros.

Após a elaboração das categorias sínteses, passou-se à construção da definição de cada categoria ou área temática, evidenciando as regras de inclusão e exclusão de forma clara para a posterior classificação, como orienta Carlomagno e Rocha (2016). Para os autores, é primordial que os pesquisadores deixem explícita a objetividade da classificação, explicando o significado de cada categoria temática. "Por mais intuitivo que possa parecer, quais são os limites de dada categoria devem ser claros e formalizados" (CARLOMAGNO; ROCHA, 2016, p. 178).

Diante disso, apesar de algumas definições já se mostrarem evidentes a partir do enunciado da categoria, seguem as definições de todas as áreas temáticas a fim de suprimir qualquer imprecisão:

1) Apoio ao Presidente da República Jair Bolsonaro - refere-se às postagens que expressam apoio e defesa tanto à figura política quanto à figura pessoal de Jair Bolsonaro e também às ações governamentais. Nessa categoria também foram incluídas todas as postagens de apoio à família do presidente.

2) Crítica ao Presidente da República Jair Bolsonaro - refere-se às postagens que criticam tanto a figura política quanto às ações governamentais de Jair Bolsonaro. A ocorrência de críticas à figura pessoal de Bolsonaro, de forma desvinculada a sua posição política, não foi observada nas postagens.

3) Apoio à demissão do Ministro da Saúde Luiz Henrique Mandetta - compreende as postagens que apoiam a decisão de demissão do ministro em decorrência de divergências com o Presidente da República Jair Bolsonaro. 
4) Crítica à demissão do Ministro da Saúde Luiz Henrique Mandetta - compreende as postagens que criticam a saída do ministro em decorrência de divergências com o Presidente da República Jair Bolsonaro.

5) Apoio às medidas sanitárias contra a propagação do novo coronavírus - referese às postagens que apoiam as medidas, cientificamente comprovadas, contra a propagação do novo coronavírus, como o uso de máscaras e o isolamento social. Essa categoria também abrange os posts em defesa das pesquisas científicas acerca da Covid19 e críticas em relação ao negacionismo científico.

6) Crítica às medidas sanitárias contra a propagação do novo coronavírus e negacionismo científico - refere-se às postagens que fazem críticas às medidas, cientificamente comprovadas, contra a propagação do novo coronavírus, como o uso de máscaras e $\mathrm{o}$ isolamento social. Essa categoria também abrange os posts contrários às pesquisas científicas e discursos negacionistas como a recusa em aceitar o número de óbitos em decorrência da Covid-19.

7) Solidariedade às vítimas da Covid-19 - compreende as postagens que demonstram solidariedade tanto às pessoas que se contaminaram com a Covid-19 desenvolveram os sintomas da doença mas sobreviveram, como aos familiares dos mortos em decorrência do novo coronavírus. Nessa categoria também foram incluídas as postagens que expressam solidariedade aos profissionais da saúde que tiveram seu trabalho intensificado devido à pandemia.

8) Defesa dos direitos das mulheres - refere-se às postagens em defesa dos direitos das mulheres, como denúncias de agressão física e psicológica e notícias relacionadas à luta pela ampliação do papel das mulheres na sociedade e a igualdade de condições entre os gêneros.

9) Ataque a adversários do Presidente da República Jair Bolsonaro - compreende as postagens com ataques a toda figura política, pessoal ou mesmo ao sistema judiciário que represente um adversário contra o Presidente da República Jair Bolsonaro ou ao exercício do seu governo, segundo a concepção do autor do post.

10) Outros - compreende as postagens cujos temas não possam ser classificados entre as nove categorias anteriores. Para uma melhor identificação do conteúdo desse grupo, os posts que estiverem nessa classificação terão seus temas identificados à parte. A criação dessa categoria é apontada por Carlomagno e Rocha (2016, p.180-181) como usual: "Por mais precisas que sejam suas categorias, sempre há algum conteúdo que não 
se encaixa em nenhuma - para isto serve esta categoria. Contudo, ela precisa ser residual, isto é, apenas sobras."

Dadas as explicações sobre os critérios de análise, segue a tabela com a classificação dos dados de acordo com as áreas temáticas identificadas.

Tabela 1 - Classificação das postagens por categorias temáticas

\begin{tabular}{|c|c|c|}
\hline Categorias temáticas & Grupo A & Grupo B \\
\hline $\begin{array}{l}\text { Tema } 1 \text { - Apoio ao } \\
\text { Presidente da República } \\
\text { Jair Bolsonaro }\end{array}$ & ausente & 43 postagens \\
\hline $\begin{array}{l}\text { Tema } 2 \text { - Crítica ao } \\
\text { Presidente da República } \\
\text { Jair Bolsonaro }\end{array}$ & 41 postagens & ausente \\
\hline $\begin{array}{l}\text { Tema } 3 \text { - Apoio à } \\
\text { demissão do Ministro da } \\
\text { Saúde Luiz Henrique } \\
\text { Mandetta }\end{array}$ & ausente & 20 postagens \\
\hline $\begin{array}{l}\text { Tema } 4 \text { - Crítica à } \\
\text { demissão do Ministro da } \\
\text { Saúde Luiz Henrique } \\
\text { Mandetta }\end{array}$ & 21 postagens & ausente \\
\hline $\begin{array}{l}\text { Tema } 5 \text { - Apoio às } \\
\text { medidas sanitárias contra } \\
\text { a propagação do novo } \\
\text { coronavírus }\end{array}$ & 48 postagens & ausente \\
\hline $\begin{array}{l}\text { Tema } 6 \text { - Crítica às } \\
\text { medidas sanitárias contra } \\
\text { a propagação do novo } \\
\text { coronavírus e } \\
\text { negacionismo científico }\end{array}$ & ausente & 8 postagens \\
\hline $\begin{array}{l}\text { Tema } 7 \text { - Solidariedade às } \\
\text { vítimas da Covid-19 }\end{array}$ & 12 postagens & 2 postagens \\
\hline $\begin{array}{l}\text { Tema } 8 \text { - Defesa dos } \\
\text { direitos das mulheres }\end{array}$ & 6 postagens & ausente \\
\hline
\end{tabular}


REVISTA PAUTA GERAL

ESTUDOS EM JORNALISMO

10.5212/RevistaPautaGeral.v.7.17118.115

四

PautaGeral

Estudos em Jornalismo

\begin{tabular}{|c|c|c|}
\hline $\begin{array}{l}\text { adversários do Presidente } \\
\text { da República Jair } \\
\text { Bolsonaro }\end{array}$ & ausente & 56 postagens \\
\hline Outros & $\begin{array}{l}\quad 22 \text { postagens } \\
\text { Temas: } \\
\text { - Entrevista com Dilma } \\
\text { Rousseff contra } \\
\text { impeachment que ela } \\
\text { sofreu; } \\
\text { - Apoio aos jornalistas do } \\
\text { programa Roda Viva (TV } \\
\text { Cultura) que criticaram o } \\
\text { governo de Bolsonaro; } \\
\text { - Publicações contra o } \\
\text { racismo; } \\
\text { - Protesto contra notícia de } \\
\text { juiz que confundiu } 26 \text { mil } \\
\text { com } 256 \text { milhões em } \\
\text { inventário de Marisa } \\
\text { Letícia; } \\
\text { - Protesto contra notícia de } \\
\text { blogueira bolsonarista que } \\
\text { diz que pessoas que } \\
\text { buscam auxílio de R } \$ \\
600,00 \text { não gostam de } \\
\text { trabalhar; } \\
\text { - Publicações em defesa } \\
\text { dos direitos dos indígenas; } \\
\text { - Publicações contra a } \\
\text { violência nas carreatas } \\
\text { dos apoiadores de Jair } \\
\text { Bolsonaro. }\end{array}$ & $\begin{array}{l}\quad 21 \text { postagens } \\
\text { Temas: } \\
\text { - crítica à imprensa por } \\
\text { reportagens contra o } \\
\text { Bolsonaro; } \\
\text { - pedido de intervenção do } \\
\text { Exército Militar; } \\
\text { - gráficos que indicam que } \\
\text { o Brasil tem menor número } \\
\text { de mortes de Covid-19 e } \\
\text { atribuição à algo } \\
\text { sobrenatural; } \\
\text { - Publicações sobre o } \\
\text { cantor Gustavo Lima (que } \\
\text { declarou apoio ao } \\
\text { Bolsonaro); } \\
\text { - Apoio ao presidente } \\
\text { americano Donald Trump; } \\
\text { - Publicações contra } \\
\text { manifestações populares } \\
\text { em frente ao quartel. } \\
\text { - Publicações pedindo } \\
\text { para as participantes do } \\
\text { grupo não usarem o } \\
\text { símbolo de hashtags (\#). }\end{array}$ \\
\hline
\end{tabular}

Fonte: elaborada pelos autores. 
A partir dos dados analisados, é possível observar a presença de comportamentos polarizados, de acordo com a linha política adotada, com uma clara divisão temática e antagônica entre os grupos. Como observa Machado e Miskolci (2019), no lugar da pluralidade e diversidade de opiniões, as redes sociais e demais plataformas on-line incentivam a reiteração de convicções que modulam as relações sociais. Com isso, constata-se não só uma polarização no âmbito político, mas também relacionada a outras áreas como as questões de saúde e, mais especificamente, à atual pandemia de Covid19.

Enquanto o Grupo $A$, que se originou pela oposição à candidatura de Jair Bolsonaro apresenta 48 postagens em apoio e incentivo às medidas sanitárias contra a propagação do novo coronavírus, o Grupo $\mathrm{B}$, formado para se posicionar favoravelmente ao então candidato, mantém-se ausente dessa perspectiva temática, e opta pelo caminho oposto - a crítica às medidas propostas, com oito publicações. Entre essas, ressalta-se que todas possuem algum elemento de promoção à desinformação, como contestações a laudos de exames para a Covid-19; vídeos que mostram hospitais vazios e dizem que a pandemia não existe; publicações contra a Organização Mundial da Saúde (OMS); afirmações que hospitais estão declarando a causa de morte como Covid-19 no lugar de outra doença e declarações explícitas de que o isolamento é uma farsa e que a culpa é da grande mídia.

Nesse ponto é significativo notar que mesmo uma notícia verídica pode se tornar a base para distorcer uma informação factível, como pode ser visto na publicação abaixo:

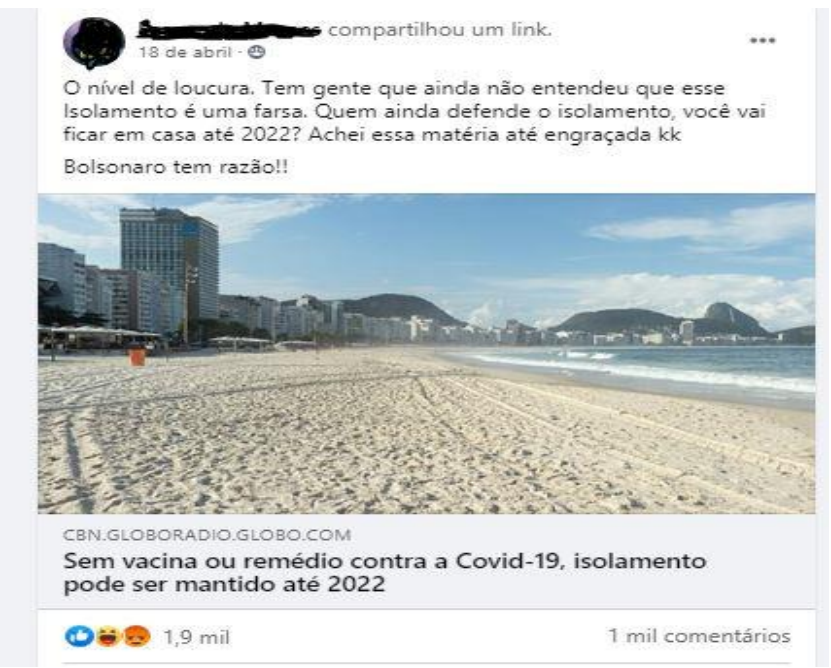

Figura 1: Post de integrante do Grupo B dizendo que o isolamento social é uma farsa. 
A usuária da rede compartilha um post da Central Brasileira de Notícias (CBN) sobre a possibilidade do isolamento ser mantido até 2022 caso não seja encontrada uma vacina ou remédio eficaz contra a Covid-19. A notícia é verídica, porém, ao compartilhá-la, a integrante do Grupo B usa a manchete como argumento para defender a posição de que "esse isolamento é uma farsa". O post publicado em 18 de abril de 2020 foi um dos que tiveram maior engajamento no dia, com 1,9 mil curtidas e 1 mil comentários, entre os quais observa-se a reiteração da posição da autora da postagem pelas outras participantes que defendem a reabertura das atividades produtivas.

Outra categoria temática que aponta para o antagonismo dos dois grupos, também na área sanitária, refere-se à demissão do então Ministro da Saúde Luiz Henrique Mandetta, no dia 16 de abril de 2020, devido aos desentendimentos com o Presidente da República Jair Bolsonaro, um dos acontecimentos mais polêmicos no contexto pandêmico brasileiro. A saída do ministro após uma série de embates com Bolsonaro, que não aceitava que Mandetta seguisse as recomendações da OMS, acirrou ainda mais a guerra não só contra a pandemia mas, principalmente, a batalha ideológica entre os defensores das medidas de controle da pandemia e os seus opositores, como pontua Caponi (2020).

A presença de dois polos opostos na questão sanitária, alinhados de acordo com a posição politica-ideológica, fica evidente na classificação dos dados. No período analisado, considerando as 150 postagens mais relevantes de cada grupo durante os cinco dias que se seguiram após a demissão de Mandetta, constata-se que o Grupo A publicou 21 postagens criticando a sua saída enquanto no Grupo B há 20 posts apoiando a demissão. Dessa forma, se por um lado nota-se um equilíbrio quantitativo nas publicações dos dois grupos acerca do assunto - Grupo A com 21 posts e Grupo B com 20 - por outro, é claramente identificado o posicionamento antagônico. As ausências também são constatadas nos dois grupos, ou seja, não há posts de apoio à demissão no Grupo A nem de críticas no Grupo B. Assim, percebe-se que os grupos apresentam uma homogeneidade em suas respectivas posições, reforçando as identidades que definem os dois coletivos.

Nesse contexto, é possível verificar que o eixo argumentativo principal do Grupo B é a figura política ou pessoal de Jair Bolsonaro. Como em sua origem, no momento da campanha eleitoral, o coletivo continua aderindo a todos os posicionamentos do agora presidente, o que também se reflete, atualmente, no tratamento da questão pandêmica. 
Assim, o fato da demissão de um Ministro da Saúde no meio de uma pandemia, mesmo com todos os protestos das autoridades médicas, não foi suficiente para levantar nenhum questionamento no Grupo B. Pelo contrário, todos os posts publicados apoiaram a demissão embasando-se no argumento de que Bolsonaro, como chefe de estado, tem razão e zela pelo bem-estar de seu povo.

Ainda em relação à demissão de Mandetta durante a pandemia do novo coronavírus, a partir da equivalência quantitativa da publicação de posts entre o Grupo A e $B$, sendo o primeiro de crítica e o segundo de apoio, é possível inferir que o tema teve a mesma proporcionalidade de importância para os dois coletivos. No entanto, é oportuno ressaltar que a saída do Ministro da Saúde na ocasião gerou intensas reações de protesto em diversos segmentos políticos e sociais, inclusive em âmbito internacional. Dessa forma, esperava-se, inicialmente, que o tema também fosse repercurtir com diversos protestos no ambiente on-line, principalmente, considerando o papel ativista a que o Grupo A se propõe, o que não foi confirmado pelo número pouco expressivo de posts publicados sob essa temática no material analisado.

De volta à análise comparativa entre os grupos, a última categoria temática relacionada à pandemia também se destaca pela disparidade, que é a solidariedade às vítimas da Covid-19. No Grupo A foram identificadas 12 postagens com esse tema e no Grupo $B$ apenas 2 publicações, sendo uma referente à morte de um médico que, segundo a autora do post, apoiava o Bolsonaro e a outra sobre servidores da saúde em Porto Velho, Rondônia, que estariam trabalhando normalmente mesmo estando infectados. $O$ baixo número de postagens que expressam solidariedade às vítimas da Covid-19 no Grupo B pode ser explicado, mais uma vez, pelo alinhamento do coletivo com as posições político-ideológicas do atual presidente que em seus discursos minimizou a gravidade da pandemia, assim como o sofrimento de suas vítimas, conforme abordado no contexto político e pandêmico.

\section{Considerações finais}

A partir da pesquisa realizada é possível inferir que a polarização política existente antes do início da pandemia do novo coronavírus reflete-se em uma polarização nos comportamentos individuais e coletivos frente à adoção das medidas de enfrentamento da Covid-19. As redes sociais, em especial o Facebook, antes usadas para a mobilização em torno de pautas essencialmente políticas, agora também são empregadas pelos seus 
usuários para reforçarem posicionamentos a respeito das questões sanitárias referentes à pandemia.

Nessa perspectiva, da mesma forma que a desinformação desempenhou um papel decisivo para a ascensão política de grupos conservadores alicerçados no negacionismo científico, agora com a pandemia, a disseminação de notícias falsas ou com conteúdos contrários aos comprovados pela ciência representa um dos principais obstáculos contra a aceitação das estratégias de proteção contra o novo coronavírus. O expressivo compartilhamento de postagens que questionam a gravidade da pandemia, assim como a adoção das ações para o seu combate, encontrado no Grupo B, demonstra a circulação da desinformação nas redes e o seu potencial de engajamento pelas participantes do coletivo.

Além disso, constata-se que os atos e discursos do atual Presidente da República Jair Bolsonaro, minimizando o poder letal do novo vírus, repercute de forma significativa entre os seus apoiadores. Dessa forma, evidencia-se que os posicionamentos do chefe de estado se sobressaem até mesmo às informações divulgadas pela mídia tradicional ou por órgãos oficiais. Ou seja, as participantes do grupo feminino, que o apóiam, aderem às posições do presidente mesmo quando suas opiniões se confrontam com informações comprovadamente científicas. Assim, a pandemia do novo coronavírus somente exacerbou as crises políticas e sociais que já existiam no país.

Com o presente estudo, buscou-se contribuir para uma reflexão necessária sobre as relações sociais no ambiente on-line, tendo em vista o contexto político e pandêmico nacional. Até o momento de encerramento da pesquisa (14 de novembro de 2020, às 22h52), o Brasil apresenta 5.848.956 casos confirmados e 165.658 óbitos $^{8}$, com 818 novas mortes nas últimas $24 \mathrm{~h}$, sendo o segundo país com mais óbitos registrados pela Covid-19, atrás apenas dos Estados Unidos, que no momento tem 244.932 óbitos confirmados. Nesse cenário, certamente, será necessária a realização de pesquisas futuras para analisar os impactos da desinformação e do negacionismo científico no enfrentamento da atual pandemia, a custo de milhares de vidas perdidas diariamente.

8 Disponível em: < https://covid.saude.gov.br/ >. Acesso em 14 de novembro de 2020. 


\section{Referências}

AGÊNCIA O GLOBO. Covid-19: Estudo liga comportamento de Bolsonaro a 10\% das mortes no Brasil, Último Segundo IG, São Paulo, 04 mai. 2020. Disponível em:

$<$ https://ultimosegundo.ig.com.br/brasil/2020-05-04/covid-19-estudo-liga-comportamentode-bolsonaro-a-10-das-mortes-no-brasil.html >. Acesso em 14 de novembro de 2020.

ANGELUCI, Alan César Belo. Características e habilidades no ambiente digital: a cultura participativa sob os aportes de Jenkins e Murray. Comunicação \& Inovação, v.15, n.29, p. 51-60, jul-dez, 2014.

BARDIN, Laurence. Análise de conteúdo. São Paulo: Edições 70, 2016.

BRASIL, Ministério da Saúde. Painel coronavírus. Disponível em: $<$ https://covid.saude.gov.br/>. Acesso em 14 de novembro de 2020.

CARLOMAGNO, Márcio C.; ROCHA, Leonardo C. Como criar e classificar categorias para fazer análise de conteúdo: uma questão metodológica. Revista Eletrônica de Ciência Política, v.7, n.1, p. 173-188, 2016.

CAPONI, Sandra. Covid-19 no Brasil: entre o negacionismo e a razão neoliberal. Estudos Avançados, São Paulo, v.34, n.99, p.209-224, 2020.

DELMAZO, Caroline; VALENTE, Jonas C. L. Fake news nas redes sociais online: propagação e reações à desinformação em busca de cliques. Media \& Jornalismo, v.18, n.32, p. 155-169, 2018.

FERRAZ, Luiz Marcelo L. Saúde e política na crise da Covid-19: apontamentos sobre a pandemia na imprensa brasileira. Reciis - Revista Eletrônica de Comunicação, Informação e Inovação em Saúde, Rio de Janeiro, v.14, n.2, p. 273-278, 2020.

JANSEN, Roberta; LAGO, Cecília. Mulheres se unem nas redes contra Bolsonaro. 0 Estado de S. Paulo, São Paulo, 13 set. 2018. Política. Disponível em: $<$ https://politica.estadao.com.br/noticias/eleicoes, mulheres-se-unem-nas-redes-contrabolsonaro,70002500084 >. Acesso em 14 de novembro de 2020.

LIMA, Nísia T; BUSS, Paulo M; PAES-SOUSA, Rômulo. A pandemia de Covid-19: uma crise sanitária e humanitária. Cadernos de Saúde Pública, Rio de Janeiro, 2020.

Disponível em: < http://cadernos.ensp.fiocruz.br/csp/artigo/1116/a-pandemia-de-covid-19uma-crise-sanitaria-e-humanitaria >. Acesso em 15 de novembro de 2020.

MACHADO, Jorge; MISKOLCI, Richard. Das jornadas de junho à cruzada moral: o papel das redes sociais na polarização política brasileira. Sociologia \& Antropologia, Rio de Janeiro, v.9, n.3, p. 945-970, 2019.

PIRES, Desirée; MOTTA, Amanda. Todo espaço é político: ativismo de mulheres nas redes sociais. Docência e Cibercultura, Rio de Janeiro, v.4, n.2, p.143-160, 2020. 
POLAT, Rabia Karakaya. The internet and political participation: exploring the explanatory links. European Journal of Communication, v. 20, n. 4, p. 435-459, 2005.

SOUZA JÚNIOR, João Henriques et al. Da desinformação ao caos: uma análise das Fake News frente à pandemia do Coronavírus (Covid-19) no Brasil. Cadernos de Prospecção, Salvador, v.13, n.2, p.331-346, 2020.

SOUSA, Maíra; RACHIT, Breda. Mobilizações pré-eleições presidenciais 2018 no Pará: grupos e eventos relacionados à \#EleNão no Facebook. Aturá Revista Pan-Amazônica de Comunicação, Palmas, v. 3, n. 1, p. 66-86, 2019.

THOMPSON, John B. Ideologia e Cultura Moderna: teoria social crítica na era dos meios de comunicação de massa. Petrópolis, RJ: Vozes, 2011.

Submissão: 15 nov. 2020.

Aceite: 06 jan 2021. 